\title{
Diagnóstico da gestão da manutenção em indústrias de médio e grande porte da região metropolitana de Recife
}

\author{
Ana Carla Bittencourt Reis ${ }^{a *}$, Ana Paula Cabral Seixas Costa ${ }^{b}$, Adiel Teixeira de Almeida ${ }^{c}$ \\ a*anacarlabr@yahoo.com.br, UFBA, Brasil \\ bapcabral@hotmail.com, UFPE, Brasil \\ calmeidaatd@gmail.com, UFPE, Brasil
}

\begin{abstract}
Resumo
Este artigo apresenta os resultados de uma investigação acerca das práticas de gerenciamento da manutenção nas indústrias de manufatura de médio e grande porte da Região Metropolitana de Recife, nos diversos ramos de atividade. A pesquisa foi realizada por meio da aplicação in loco de um questionário que aborda questões importantes do contexto da manutenção. As 50 indústrias entrevistadas foram selecionadas por meio de uma amostragem probabilística cuja estrutura foi extraída do cadastro da Federação das Indústrias do Estado de Pernambuco (anos de 2005 e 2006). As entrevistas foram conduzidas durante o segundo e terceiro trimestres de 2007 e, dentre os resultados encontrados, pode-se afirmar que a manutenção mostrou algumas deficiências que podem ser amenizadas e até mesmo superadas por meio de uma maior atenção a esse setor. Além disso, pode-se destacar que grande parte das indústrias utiliza a experiência gerencial como ferramenta de análise em detrimento de técnicas analíticas mais eficientes para a solução de problemas. Esse comportamento limita os resultados positivos que podem ser obtidos a partir de um tratamento adequado da manutenção.
\end{abstract}

Palavras-chave

Gestão da manutenção. Estratégia da manutenção. Planejamento da manutenção.

\section{Introdução}

0 presente artigo expõe os resultados de uma pesquisa que descreve a situação da gestão da manutenção em indústrias de manufatura da região metropolitana de Recife (RMR). A RMR corresponde a uma área de $2.768,955 \mathrm{~km}^{2}$, com uma população de 3.730.397 habitantes (INSTITUTO..., 2007) e abrange os seguintes municípios do estado de Pernambuco: Recife, Jaboatão dos Guararapes, Olinda, Paulista, Abreu e Lima, Igarassu, Camaragibe, Cabo de Santo Agostinho, São Lourenço da Mata, Araçoiaba, Ilha de Itamaracá, Ipojuca, Moreno e Itapissuma.

Foram investigadas as indústrias de manufatura de médio e grande porte, conforme classificação do Sebrae (Tabela 1), a qual se baseia no número de funcionários.

Os aspectos investigados envolveram treinamentos, planejamento (ALMEIDA; BOHORIS, 1995), estratégia da manutenção (PINTELON; KUMAR; VEREECKE, 2006; ALMEIDA, 2005), custos, terceirização da manutenção (ALMEIDA, 2001; VALOIS; ALMEIDA, 2009), dimensionamento de sobressalentes, estrutura organizacional (SZAJUBOK et al., 2006) e outras questões relacionadas à manutenção (PARIDA; KUMAR, 2006; CAVALCANTE; ALMEIDA, 2007, 2005; REIS; COSTA; ALMEIDA, 2009; SANTOS, 2001).

Em seu artigo sobre a análise de desempenho da manutenção, Groote (1995) relata que um exame de qualidade da manutenção significa fornecer alguma ideia sobre sua performance mediante uma avaliação dos problemas existentes, do ponto de vista operacional e organizacional, para ser capaz de mensurar e iniciar um plano de ação. E ainda, de acordo com Parida e Kumar (2006), o que não pode ser medido não pode ser gerenciado, efetivamente. Dessa forma, 
para que os gerentes de operação possam gerenciar os processos de manutenção e os próprios recursos é preciso medir a contribuição da manutenção para os objetivos do negócio.

A gestão da manutenção tem sido objeto de muitos estudos como, por exemplo, a pesquisa-piloto sobre o status da gestão da manutenção em empresas de manufatura do Reino Unido realizado por Cholasuke, Bhardwa e Antony (2004). Esse trabalho conclui que a manutenção assume um papel crítico como suporte das atividades de manufatura e que um aceitável nível de performance das indústrias é inalcançável sem o efetivo suporte da gestão da manutenção. Outra pesquisa, realizada por Jonsson (1997), buscou analisar o status da gestão da manutenção em empresas de manufatura da Suécia. Como resultado, tem-se que um terço das firmas considera de pouca importância o setor de manutenção, e que isso é um grande obstáculo para proporcionar aprendizagem e trabalhar por melhorias contínuas.

Dados da Associação Brasileira de Manutenção (ASSOCIAÇÃO..., 2007) mostram que 41,17\% das empresas no Brasil não desenvolvem atividade de engenharia de manutenção e, dentre as que desenvolvem, cerca de $25 \%$ dos funcionários não possuem nem ao menos o nível técnico. Esses, dentre outros números encontrados na pesquisa, mostram que é incipiente e escassa a utilização de técnicas mais adequadas à gestão da manutenção e também, de procedimentos que possibilitem melhoras na produção.

No Brasil foram encontrados poucos estudos abordando o tema em questão e, quanto à RMR, não foi encontrado nenhum registro que retrate a situação das indústrias de manufatura no contexto do gerenciamento da manutenção. Dessa forma, um diagnóstico da gestão da manutenção na RMR pode trazer grandes benefícios, pois expõe as características e práticas ineficientes atualmente utilizadas nas organizações e, consequentemente, incentiva ações que proporcionem melhorias significativas.

Os itens a seguir apresentam a metodologia utilizada na pesquisa, uma breve descrição das questões consideradas relevantes para a função manutenção, a análise descritiva e exploratória dos dados, a hipótese construída, uma discussão sobre os resultados encontrados, as conclusões e as limitações e sugestões para trabalhos futuros.

Tabela 1. Classificação das indústrias quanto ao porte.

\begin{tabular}{lc}
\hline Classificação das indústrias & Número de funcionários \\
\hline Microempresa & de 1 a 19 \\
Pequenas Empresas & de 20 a 99 \\
Médias Empresas & de 100 a 499 \\
Grandes Empresas & a partir de 500 \\
\hline Fonte: Sebrae (2006). &
\end{tabular}

\section{Metodologia}

A pesquisa é um meio que permite esclarecer aspectos de interesse do pesquisador, assim como coletar dados para diferentes tipos de análise e, também, para averiguar hipóteses construídas.

A metodologia utilizada nesta pesquisa envolve as etapas a seguir:

\section{$1^{\text {a }}$ - Definição da população-alvo}

0 primeiro passo da pesquisa foi a definição da população-alvo desta investigação: as indústrias de manufatura de médio e grande porte localizadas na RMR, nos vários ramos de atividade existentes, com exceção das empresas de construção civil.

\section{$2^{\text {a }}$ - Definição do plano de pesquisa}

Um plano de pesquisa é útil para fornecer as orientações básicas sobre como se deve proceder na condução de uma investigação (HAIR JUNIOR et al., 2005). Por se tratar de um procedimento que visa mensurar, ou seja, relatar o objeto de estudo, o plano escolhido para apoiar a pesquisa foi o descritivo.

\section{$3^{\text {a }}$ - Escolha do método de coleta de dados}

As características da população pesquisada foram levantadas por meio de entrevistas, a partir da aplicação de um questionário, o qual abordou os diferentes aspectos do contexto da gestão da manutenção, conforme apresentados ao longo do trabalho. As perguntas que compõem o questionário foram desenvolvidas de pesquisa bibliográfica e abordam aspectos da manutenção considerados relevantes.

0 método utilizado para a administração do questionário foi a realização de uma entrevista estruturada, o que possibilitou coletar os dados de maneira sistemática e numa sequência padronizada para todos os entrevistados. Desse modo foi possível dar a mesma oportunidade de resposta e evitar tendências relacionadas à forma de arguição.

0 questionário foi apresentado diretamente ao indivíduo responsável pela manutenção, devido ao contato e acesso a todas as atividades relacionadas e por, supostamente, ser o tomador das decisões. A entrevista foi realizada pessoalmente, por meio de visitas às empresas, por tal método de administração do questionário possibilitar uma alta taxa de resposta, além de evitar interpretações enganosas sobre as questões formuladas.

\section{$4^{\mathrm{a}}$ - Processo de amostragem}

Busca-se com a amostragem observar um subconjunto da população em análise que permita estabelecer conclusões sobre a população.

0 processo de amostragem foi realizado tomando-se como base os passos definidos em Hair Junior et al. (2005), conforme a seguir:

a) Escolha da estrutura de amostragem

A estrutura de amostragem diz respeito a uma lista abrangente dos elementos que compõem a 
amostra (HAIR JUNIOR et al., 2005). Para compor a estrutura de amostragem foi acessado o cadastro da Federação das Indústrias do Estado de Pernambuco (Fiepe) referente aos anos 2005 e 2006. Esse cadastro procura listar todas as indústrias de Pernambuco, distribuídas dentre os diversos setores da economia, segundo uma classificação feita pela própria Federação.

\section{b) Seleção do método de amostragem}

0 método de amostragem utilizado na pesquisa foi o probabilístico, realizado pela seleção aleatória das empresas a serem entrevistadas, com o intuito de tornar a amostra representativa.

A amostragem (probabilística) aleatória estratificada é um método onde a população-alvo é subdividida em estratos homogêneos segundo algum critério. Essa condição visa assegurar a aleatoriedade do processo de amostragem de modo que, uma vez repetida a pesquisa, utilizando-se os mesmos procedimentos, sejam obtidos os mesmos resultados. Os estratos devem resguardar a característica de serem mutuamente excludentes, para que não haja reposição na amostragem. Além disso, a estratificação é um mecanismo que permite a redução da heterogeneidade e, consequentemente, aumenta a precisão da estimativa (SUKHATME; SUKHATME, 1970).

A população investigada foi dividida em estratos distintos e amostras aleatórias simples, as quais atribuem a mesma probabilidade de seleção aos elementos da população, foram extraídas de cada um deles.

A estratificação da população teve como critério de classificação o atributo porte da indústria, conforme categorias determinadas pelo Sebrae. Outra opção de estratificação poderia ser o critério ramo de atividade, porém determinados ramos de atividade possuem características extremamente distintas com relação ao porte da indústria. Em alguns casos, como nas empresas de pequeno porte, há indústrias que sequer possuem um setor dedicado à manutenção. Sendo assim, para este trabalho foram consideradas apenas as indústrias de manufatura classificadas como Médias e Grandes Empresas.

No estrato das Médias Empresas foi realizado um agrupamento pelo ramo de atividade, por se tratarem de 29 ramos distintos. Esses 29 ramos foram reagrupados de acordo com as semelhanças nos tipos de atividade desenvolvida, a fim de assegurar a homogeneidade de cada conjunto de empresas e garantir o sucesso da amostragem. Como resultado, restaram treze conjuntos de empresas mutuamente excludentes. Amostras aleatórias sem reposição foram extraídas de cada um deles, respeitando-se a proporção de cada grupo em relação à população em estudo.
Já para o estrato das Grandes Empresas percebeu-se que aproximadamente $50 \%$ delas pertenciam a um único ramo de atividade, o da fabricação de produtos alimentícios e bebidas. As demais empresas eram de ramos diversificados. Por se tratar de uma população relativamente pequena, foi adotado o procedimento de extração de uma amostra proporcional a esses dois grupos de empresas.

c) Definição do tamanho da amostra e implementação do plano de amostragem

A determinação do tamanho da amostra é uma etapa extremamente importante do processo de amostragem, já que influi diretamente na precisão das informações produzidas e generalização das descobertas. Existem fórmulas estatísticas que possibilitam calcular o tamanho da amostra para o parâmetro de interesse. Contudo, para aplicá-las é preciso determinar o erro amostral máximo tolerado $\left(E_{0}\right)$, o nível de confiança $(\gamma)$ a ser adotado e a variância populacional $\left(\sigma^{2}\right)$.

Geralmente, encontra-se bastante dificuldade na determinação da variância da população. Em alguns problemas ela pode ser avaliada por meio de estudos anteriores sobre a mesma população (BARBETTA; REIS; BORNIA, 2004; COCHRAN, 1977), por conjeturas acerca da estrutura da população, ajudadas por fórmulas matemáticas, ou pelos resultados de um levantamento-piloto (COCHRAN, 1977).

Por não ter sido encontrado em Pernambuco nenhum estudo semelhante a este, não houve qualquer dado que indicasse o desvio padrão das variáveis envolvidas, o qual pudesse servir de base inicial para o cálculo do tamanho da amostra. A opção mais coerente foi a realização de uma amostragem-piloto. Nesse caso, a variância da amostra-piloto foi generalizada para a população em estudo.

Uma vez colhidos os dados para a amostragempiloto, foi aplicada a Equação 1 para o cálculo do valor inicial do tamanho da amostra (BARBETTA; REIS; BORNIA, 2004):

$n_{0}=\frac{z_{\gamma}^{2} \sigma^{2}}{E_{o}^{2}}$

Em que:

- $n_{0}$ é o tamanho inicial da amostra

- $Z_{\gamma}$ é a estatística do teste

- $\sigma^{2}$ é a variância populacional

- $E_{o}$ é o erro amostral máximo tolerado

Por se tratar de uma população finita, com o seu tamanho, denominado N, conhecido, procedeu-se à 
correção do valor de $n_{0}$, conforme indica a Equação 2 (BARBETTA; REIS; BORNIA, 2004):

$$
n=\frac{N \cdot n_{o}}{N+n_{0}-1}
$$

Esta pesquisa envolve mais de uma especificação e, diante dessa circunstância, de acordo com Cochran (1977), um dos processos para se determinar a grandeza da amostra é estabelecer as margens de erro para as especificações consideradas mais importantes para o levantamento. A partir daí, foram verificados os valores encontrados de $n$ para os atributos considerados relevantes e que também possuem os requisitos necessários para a aplicação das fórmulas.

Para as Grandes Empresas, cuja população encontrada na base da Fiepe é de 31 indústrias, foi obtido um $n$ igual a 10. A partir daí, procedeu-se à realização de um sorteio para selecionar as indústrias pertencentes à amostra. No caso das Médias Empresas, cuja população é de 122 indústrias, o $n$ calculado para alguns atributos ficou em torno de 30 . Decidiu-se investigar 40 empresas (selecionadas por sorteio) para se obter uma melhor representatividade.

\section{$5^{\mathrm{a}}$ - Organização dos dados}

Concluída a coleta, os dados foram cuidadosamente transportados para uma planilha eletrônica e codificados para a formação da base. A plataforma computacional utilizada como ferramenta de análise foi o software Statistica 6.0. (STATSOFT, 2001).

$6^{\text {a }}$ - Análises estatísticas e interpretação prática dos resultados

Para ambos os estratos, das Médias e Grandes Empresas, foi feita uma análise descritiva e exploratória dos dados e construída uma hipótese de forma similar a outros trabalhos encontrados na literatura e que realizaram pesquisas no Brasil (BARBOSA; ALMEIDA; COSTA, 2006; CLERICUZI; ALMEIDA; COSTA, 2006).

\section{A função manutenção}

Esse item apresenta algumas definições úteis ao contexto da função manutenção e relevantes para uma melhor compreensão do trabalho realizado.

\subsection{Ações de manutenção}

$\mathrm{Na}$ literatura podem ser encontradas diferentes classificações para as ações de manutenção empreendidas nas empresas. Neste trabalho, elas foram classificadas como preventivas, preditivas e corretivas, conforme definição a seguir.

De acordo com 0'Connor (2005), a manutenção preventiva busca reter o sistema, que está em estado operacional ou disponível, para a prevenção de falhas que podem ocorrer. A manutenção preventiva influencia diretamente na confiabilidade, é planejada e deve ser executada num instante predeterminado.

Já a manutenção preditiva, de acordo com a ABNT (ASSOCIAÇÃO..., 1994), busca garantir a qualidade de serviço desejada com base na aplicação sistemática de técnicas de análise, utilizando-se meios de supervisão centralizados ou de amostragem para reduzir ao mínimo a manutenção preventiva e diminuir a manutenção corretiva.

Por fim, a manutenção corretiva que, de acordo com 0'Connor (2005), inclui todas as ações necessárias para levar um sistema de um estado de falha para um operacional ou disponível. Ações de manutenções corretivas, usualmente, não podem ser planejadas. As falhas devem ser reparadas quando ocorrem, embora alguns reparos possam ser protelados. Conforme a ABNT (ASSOCIAÇÃO..., 1994), esse tipo de manutenção está relacionado à ocorrência de falhas aleatórias, que não podem ser detectadas ou planejadas.

\subsection{Modelos para a gestão da manutenção}

Os modelos desenvolvidos para a gestão da manutenção são diversos, por exemplo: Total Productive Maintenance (TPM), Reliability-Centered Maintenance (RCM), Condition Based Maintenance (CBM), Computerized Maintenance Management Systems (CMMS), Effectiveness Centered Maintenance (ECM), Strategic Maintenance Management (SMM) e Risk Based Maintenance (RBM) (GARG; DESHMUKH, 2006). A seguir estão descritos os modelos abordados neste trabalho:

A manutenção produtiva total (TPM) implica o envolvimento de toda a organização na otimização do processo produtivo, desde a alta gerência até os operários que trabalham no chão de fábrica, em busca de melhoria contínua da capacidade produtiva, da motivação das pessoas, do funcionamento dos equipamentos e da qualidade.

A manutenção centrada em confiabilidade (RCM) foi desenvolvida por Stanley Nowlan e Howard Heap, ambos da United Airlines, em 1978, a partir da necessidade de aumento da confiabilidade das aeronaves civis americanas (SIQUEIRA, 2005). Também chamada de manutenção baseada na confiabilidade (MBC), procura avaliar as consequências das falhas em termos gerais visando elevar a disponibilidade associada à redução dos custos e dos tempos de reparo das máquinas e equipamentos.

A metodologia RBM (manutenção baseada no risco) tem por objetivo otimizar as tarefas de manutenção, mantendo um elevado nível de disponibilidade dos 
equipamentos. Isso é conseguido por meio de um estudo de todos os possíveis modos de falha, o que determina uma estimativa realista do nível de risco associado a cada modo de falha e o desenho de uma estratégia de manutenção que minimize a ocorrência dos modos de falha de alto risco (KHAN, 2004).

\subsection{A manutenção como fonte de vantagem competitiva}

A vantagem competitiva trata do modo como uma empresa coloca em prática as estratégias genéricas. De que forma uma empresa ganha uma vantagem de custo sustentável? De que forma ela pode diferenciar-se da concorrência? (PORTER, 1992) Ainda de acordo com o autor, a vantagem competitiva não pode ser compreendida quando se observa a empresa como um todo. Ela tem sua origem nas inúmeras atividades que uma empresa executa e cada uma dessas atividades pode contribuir para a posição dos custos relativos de uma empresa. Dentre essas atividades está a manutenção. Surge então a seguinte questão (discutida neste trabalho): qual tratamento deve ser dado à área de manutenção para que ela seja percebida como uma fonte de vantagem competitiva para as organizações?

\section{Análise descritiva dos dados}

A estatística descritiva visa a identificação de medidas de posição central, dispersão e assimetria dos dados investigados. Foram analisados fatores como faturamento, estrutura funcional, estrutura da manutenção, planejamento, questões estratégicas, dentre outros.

\subsection{Faturamento}

Os dados sobre o faturamento bruto das Médias Empresas revelam uma grande dispersão (Tabela 2): variam de empresas que faturam em torno de 2 milhões a empresas que faturam cerca de 480 bilhões de reais.

Das empresas de grande porte entrevistadas, apenas 30\% dispuseram os valores referentes ao faturamento bruto anual, neles foi possível observar que esse estrato de empresas também apresentou uma alta variação com relação a esse critério.

Tabela 2. Estatísticas do faturamento das empresas de médio porte (em milhões de reais).

\begin{tabular}{cccc}
\hline Média & Desvio padrão & Mínimo & Máximo \\
\hline $2.248,25$ & $10.219,08$ & 2,00 & $480.000 .000,00$ \\
\hline
\end{tabular}

\subsection{Estrutura funcional}

Nas Médias e Grandes Empresas, tanto o número de funcionários total das empresas quanto da área de manutenção apresentou grande dispersão (Tabela 3).

\subsection{Manutenção contratada}

Em busca de disponibilidade, muitas indústrias utilizam somente pessoal próprio para a realização da manutenção. Porém, um alto contingente de pessoal alocado para a realização da manutenção tende a torná-la bastante dispendiosa. A terceirização da manutenção pode ser uma forma de minimizar custos, desde que haja um compromisso com a disponibilidade.

Nas médias e nas Grandes Empresas pesquisou-se se a manutenção era realizada por funcionários próprios, terceirizados ou ambos, conforme apresentado na Tabela 4. Vale ressaltar que em nenhum dos casos arguídos a manutenção era realizada apenas por empresa terceirizada.

Em complemento à investigação sobre a contratação da manutenção, buscou-se identificar como é feita a procura por empresas terceirizadas, se é por pesquisa de mercado, indicação ou de outra forma.

A pesquisa de mercado é uma alternativa que permite um leque mais amplo e atual de opções por possibilitar ao tomador da decisão acesso a qualquer empresa existente no mercado. Nesse caso há também a possibilidade de se analisar outros critérios que possam ser julgados importantes na seleção, enquanto a indicação prioriza, na maior parte dos casos, o critério credibilidade.

Dentre as indústrias de médio porte que utilizam a manutenção contratada, observa-se que 61\% da procura por esse serviço acontece por meio da realização de pesquisa de mercado, contra $39 \%$ de indústrias que o fazem por indicação. 0 comportamento das Grandes Empresas é semelhante.

\subsection{Dimensionamento de sobressalentes}

0 dimensionamento de sobressalentes é de extrema relevância, visto que interfere diretamente no tempo gasto para se realizar a manutenção. A Tabela 5 apresenta os resultados da investigação sobre como ele é feito.

Observa-se que nenhuma das indústrias entrevistadas considera o comportamento das falhas para realizar estudos que identifiquem a demanda por certos itens e, consequentemente, o quantitativo de 
Tabela 3. Estatísticas referentes ao número de funcionários total das indústrias e o número deles lotados na área de manutenção.

\begin{tabular}{clcccccc}
\hline \multirow{2}{*}{ Porte da indústria } & Número de funcionários & Média & Mediana & Moda & Mínimo & Máximo & Desvio padrão \\
\hline \multirow{2}{*}{ Médio } & Total & 273,62 & 275 & Múltipla & 100 & 499 & 135,23 \\
& Lotados na manutenção & 16,42 & 15,5 & 20 & 1 & 40 & 10,73 \\
\multirow{3}{*}{ Grande } & 905,8 & 729 & 700 & 500 & 1800 & 404,81 \\
& Total & 51,2 & 43,5 & 54 & 29 & 140 & 32,85 \\
\hline
\end{tabular}

Tabela 4. Origem dos funcionários responsáveis pela realização da manutenção.

\begin{tabular}{lcc}
\hline $\begin{array}{c}\text { Porte da } \\
\text { indústria }\end{array}$ & $\begin{array}{c}\text { Porcentagem de empresas que realizam manutenção } \\
\text { somente com funcionários próprios }(\%)\end{array}$ & $\begin{array}{c}\text { Porcentagem de empresas que realizam manutenção com } \\
\text { funcionários próprios e terceirizados (\%) }\end{array}$ \\
\hline Médio & 55 & 45 \\
Grande & 30 & 70 \\
\hline
\end{tabular}

Tabela 5. Critérios utilizados pelas indústrias para dimensionar sobressalentes

\begin{tabular}{lcc}
\hline $\begin{array}{c}\text { Critério para dimensionamento } \\
\text { de sobressaltentes }\end{array}$ & $\begin{array}{c}\text { Porcentagem } \\
\text { de Médias } \\
\text { Empresas (\%) }\end{array}$ & $\begin{array}{c}\text { Porcentagem } \\
\text { de Grandes } \\
\text { Empresas (\%) }\end{array}$ \\
\hline $\begin{array}{l}\text { Pela experiência gerencial } \\
\text { Pela quantidade de equipamentos } \\
\text { sob os cuidados da manutenção }\end{array}$ & 43 & 50 \\
Não é realizado & 20 & 50 \\
\hline
\end{tabular}

peças de reposição necessárias para um determinado modelo de equipamento.

\subsection{Uso de software}

Diante da diversidade de equipamentos utilizados nas indústrias e suas peculiaridades, torna-se difícil gerenciar os dados de comportamento desses equipamentos de modo a gerar informação. A utilização de softwares para apoiar o gerenciamento da manutenção é uma ferramenta de grande utilidade na gestão da manutenção por facilitar o cálculo de indicadores, a realização de estudos de confiabilidade e mantenabilidade, dentre outros aplicativos.

As empresas foram questionadas se utilizam ou não algum software no apoio à gestão da manutenção. Apenas 37,5\% das indústrias de médio porte utilizam o software, enquanto que $70 \%$ das indústrias de grande porte utilizam o fazem.

\subsection{Ações de manutenção}

Os gerentes foram questionados sobre a porcentagem de utilização das ações de manutenção (corretiva, preventiva e preditiva). Percebe-se em ambos os estratos, Médias e Grandes Empresas, que ainda são realizadas muitas manutenções corretivas. Nas indústrias de médio porte arguidas, uma média de 50\% das manutenções realizadas é corretiva e, nas de grande porte, esse percentual fica em torno de $42 \%$, conforme a Tabela 6 .

\subsection{Previsão orçamentária}

Nesta sessão são exploradas questões relativas ao orçamento dedicado à manutenção. Inicialmente foi perguntado aos gerentes se era realizada previsão orçamentária para o setor de manutenção e a reposta foi positiva para maior parte das médias (67\%) e das grandes (80\%) empresas.

Dentre as empresas que realizam previsão orçamentária, buscou-se identificar como esta é realizada: através do histórico do orçamento do período anterior; arbitrariamente, através da fixação de uma quota para manutenção; através de um planejamento orçamentário feito a cada período; ou de outra forma. Observou-se que apenas 37\% das indústrias de médio porte realizam um novo planejamento orçamentário a cada período.

Em número maior (80\%), as Grandes Empresas realizam previsão orçamentária e metade delas o faz por meio de um novo planejamento orçamentário a cada período.

Percebe-se que ainda há muitas indústrias que não fazem previsão orçamentária para a manutenção. Quando afirmam que o fazem ou utilizam o orçamento do período anterior, ou usam alguma quota fixada arbitrariamente pela organização.

\subsection{Modelos e ferramentas de gestão}

Os gerentes foram questionados sobre a utilização de metodologias de gestão como TPM, RCM e RBM. Pela Tabela 7, pode-se observar que a metodologia mais utilizada é a TPM, tanto nas médias quanto nas grandes indústrias. Porém, em geral, o uso das três metodologias é baixo. 


\subsection{Treinamentos}

É de fundamental importância o investimento em mão de obra qualificada a fim de se obter maior qualidade na realização das tarefas demandadas. Além da qualidade, funcionários devidamente treinados estão menos propensos a cometer erros e executam o serviço proposto em um período de tempo menor.

As empresas foram questionadas se realizam ou não treinamentos com seus funcionários. Observa-se que 15\% das indústrias de médio porte não oferecem treinamentos aos seus funcionários. Nas grandes indústrias, esse percentual fica em torno de 10\%.

\section{Análise exploratória dos dados}

Nesta etapa da pesquisa buscou-se explorar as possíveis associações entre as variáveis e identificar padrões de comportamento.

A investigação inicial partiu da busca por relações entre os pares de variáveis por meio da utilização de testes estatísticos. A escolha do teste estatístico para a identificação das relações levou em consideração os tipos de variáveis envolvidas na análise e o atendimento aos pressupostos exigidos por cada teste. Basicamente, aplicou-se o teste de Mann-Whitney quando uma variável era intervalar ou de razão e a outra categórica e a correlação de Spearman para os casos em que ambas as variáveis eram pelo menos ordinais.

Desde que seja atingido um grau de mensuração ao menos ordinal, pode-se aplicar a prova U de MannWhitney para comprovar se dois grupos independentes foram ou não extraídos da mesma população. Trata-se de uma das mais poderosas provas não paramétricas e constitui-se uma alternativa extremamente útil da prova paramétrica $t$, quando o pesquisador deseja evitar as suposições exigidas por esta última, ou quando a mensuração atingida é inferior à da escala

Tabela 6. Média de realização das ações de manutenção nas indústrias.

\begin{tabular}{lccc}
\hline \multirow{2}{*}{ Porte da indústria } & \multicolumn{3}{c}{ Ações de manutenção } \\
\cline { 2 - 4 } & Corretiva (\%) & Preventiva (\%) & Preditiva (\%) \\
\hline Médias Empresas & 50 & 40 & 10 \\
Grandes Empresas & 42 & 40 & 18 \\
\hline
\end{tabular}

Tabela 7. Porcentagem de empresas que utilizam metodologias de gestão.

\begin{tabular}{lcccc}
\hline \multirow{2}{*}{$\begin{array}{c}\text { Porte da } \\
\text { indústria }\end{array}$} & \multicolumn{4}{c}{ Modelos de gestão } \\
\cline { 2 - 5 } & $\begin{array}{c}\text { TPM } \\
(\%)\end{array}$ & $\begin{array}{c}\text { RCM } \\
(\%)\end{array}$ & $\begin{array}{c}\text { RBM } \\
(\%)\end{array}$ & $\begin{array}{c}\text { Nenhum modelo } \\
\text { é utilizado (\%) }\end{array}$ \\
\hline Médias Empresas & 23 & 15 & 3 & 59 \\
$\begin{array}{l}\text { Grandes } \\
\text { Empresas }\end{array}$ & 50 & 20 & 20 & 10 \\
\hline
\end{tabular}

de intervalos (SIEGEL; CASTELLAN, 1988). A hipótese nula $\left(\mathrm{H}_{0}\right)$ do teste é de que não há diferença entre as posições centrais das duas populações.

A correlação mede, numericamente, a força ou o grau de relacionamento entre duas variáveis, o que não implica, necessariamente, numa relação "causa e efeito" (STEVENSON, 2002; BARBETTA; REIS; BORNIA, 2004). A correlação por postos de Spearman, ou correlação por ordem de ranqueamento, é medida por meio do coeficiente de correlação de Spearman, designado por $\rho$ e que varia entre $-1,0$ e 1,0 . É uma medida de associação que exige que ambas as variáveis se apresentem numa escala de mensuração pelo menos ordinal e não faz nenhum pressuposto quanto à normalidade da distribuição.

0 nível de significância adotado foi 5\% e a interpretação de todos os testes foi feita baseada na análise da probabilidade de significância, o p-valor ( $p$ ) que determina a probabilidade de se rejeitar $\mathrm{H}_{0}$ quando ela for verdadeira (erro tipo 1). Assim, se $\mathrm{p}<0,05, \mathrm{H}_{0}$ é rejeitada, caso contrário o teste indica que não existem evidências suficientes para se rejeitar a hipótese nula.

As relações encontradas estão apresentadas nas Tabelas 10, 11, 12 e 13, no Apêndice 1, onde constam os testes utilizados para identificar cada uma dessas relações, assim como a estatística do teste utilizado e o respectivo $p$ valor.

\subsection{Resultados encontrados nas Médias Empresas}

\subsubsection{Uso de software}

As empresas entrevistadas foram questionadas se utilizam ou não algum software como apoio à gestão da manutenção e esse tópico apresenta algumas características dessas empresas. Os entrevistados foram solicitados a responder até que ponto concordam com as afirmativas representadas na Figura 1. Como opções de resposta utilizou-se uma escala intervalar de cinco pontos que vai desde a intensidade "discordo totalmente" a "concordo totalmente".

Todas as empresas entrevistadas que utilizam software apresentam o comportamento a seguir:

- Concordam que a estratégia da manutenção está alinhada à estratégia da empresa;

- Concordam que a manutenção traz vantagem competitiva pra a organização; e

- Concordam que a manutenção é realizada de forma planejada.

A Figura 1 apresenta as variáveis relacionadas com o uso de software. 


\subsubsection{Vantagem competitiva}

Os entrevistados foram solicitados a responder até que ponto concordavam com a afirmativa de que a manutenção traz vantagem competitiva para a organização. Como opções de resposta utilizou-se a escala da Tabela 8. A Figura 2 ilustra as relações encontradas.

As Médias Empresas que concordam (entre os pontos 4 e 5 da Tabela 8) que a manutenção traz

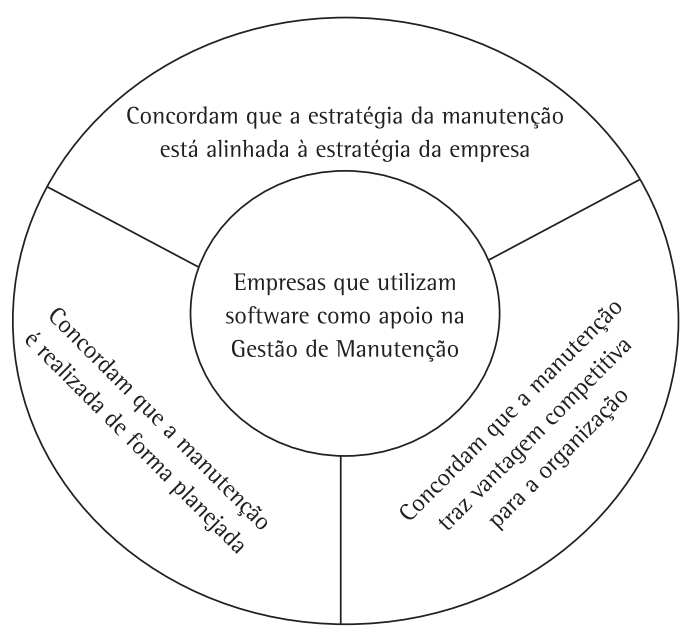

Figura 1. Atributos das Médias Empresas que utilizam software como apoio à gestão da manutenção.

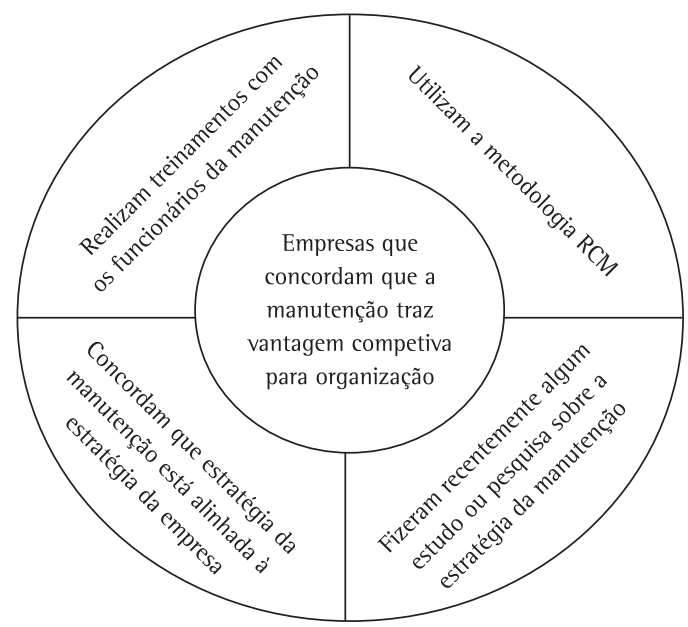

Figura 2. Variáveis características das empresas que concordam que a manutenção traz vantagem competitiva para a organização.

Tabela 8. Amplitude da escala intervalar utilizada.

\begin{tabular}{lc}
\hline \multicolumn{1}{c}{ Escala } & Pontos \\
\hline Discordo totalmente & 1 \\
Discordo & 2 \\
Não concordo nem discordo & 3 \\
Concordo & 4 \\
Concordo totalmente & 5 \\
\hline
\end{tabular}

vantagem competitiva para a organização apresentam o seguinte comportamento:

- Utilizam a metodologia RCM;

- Realizam treinamentos com os funcionários da manutenção;

- Concordam que a estratégia da manutenção está alinhada à estratégia da empresa; e

- Fizeram recentemente algum estudo ou pesquisa sobre a estratégia da manutenção.

\subsubsection{Planejamento da manutenção}

Os entrevistados foram solicitados a responder até que ponto concordavam com a afirmativa de que a manutenção é realizada de forma planejada. Como opções de resposta utilizou-se a escala da Tabela 8.

As empresas que concordam (entre os pontos 4 e 5 da Tabela 8) que a manutenção é realizada de forma planejada apresentam as seguintes relações:

- As empresas que concordam que a manutenção é realizada de forma planejada concordam que a manutenção traz vantagem competitiva para organização; e

- As empresas que utilizam a metodologia RCM concordam que a manutenção é realizada de forma planejada.

\subsubsection{Ações de manutenção utilizadas}

Os gerentes foram questionados sobre porcentagem de realização das ações de manutenção adotadas na indústria (corretiva, preventiva e preditiva). Essas variáveis apresentaram algumas relações, conforme exposto a seguir:

\subsection{Manutenção corretiva}

A realização de menos manutenções corretivas apresenta relação com algumas variáveis. A primeira relação apresentada (Figura 3) mostra que as Médias Empresas que utilizam software de apoio à gestão da manutenção realizam menos manutenções corretivas.

A realização de menos manutenções corretivas apresenta correlação inversa (Figura 4) com a concordância de que a manutenção traz vantagem competitiva para a organização (Q37).

A última associação apresentada com a realização de manutenção corretiva é em relação ao planejamento. A correlação encontrada foi negativa e alta, ou seja, as empresas que concordam que a manutenção é realizada de forma planejada realizam menos manutenção do tipo corretiva (Figura 5). 


\subsection{Manutenção preventiva}

Neste caso, a realização de mais manutenções do tipo preventiva apresenta relação com algumas variáveis. Uma das relações encontradas diz respeito ao uso de software, ou seja, as Médias Empresas que utilizam software de apoio à gestão da manutenção realizam mais manutenções preventivas (Figura 6).

Outra associação encontrada com a realização de manutenção preventiva é em relação ao planejamento, cuja correlação encontrada foi positiva e moderada. As empresas que concordam (conforme escala de cinco pontos da Tabela 8) que a manutenção é realizada de forma planejada realizam mais manutenção do tipo preventiva (Figura 7).

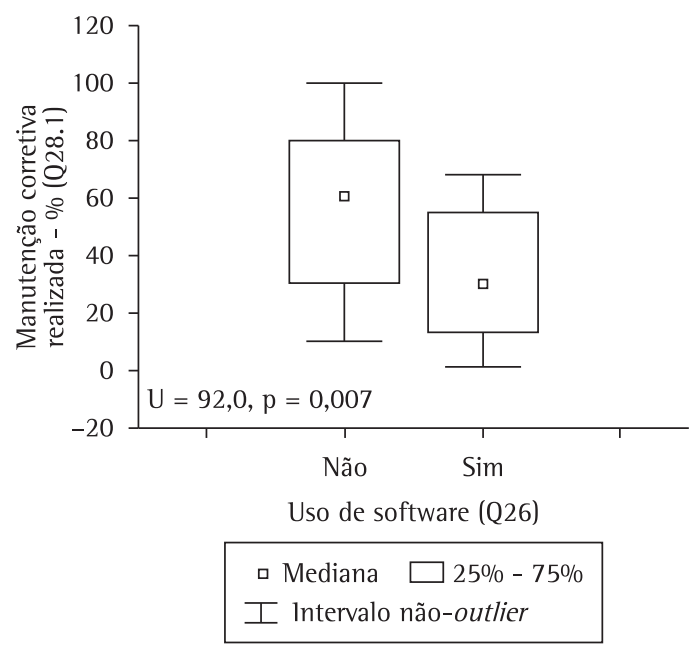

Figura 3. Porcentagem de manutenção corretiva realizada pelas Médias Empresas em relação ao uso de software de apoio à gestão da manutenção.

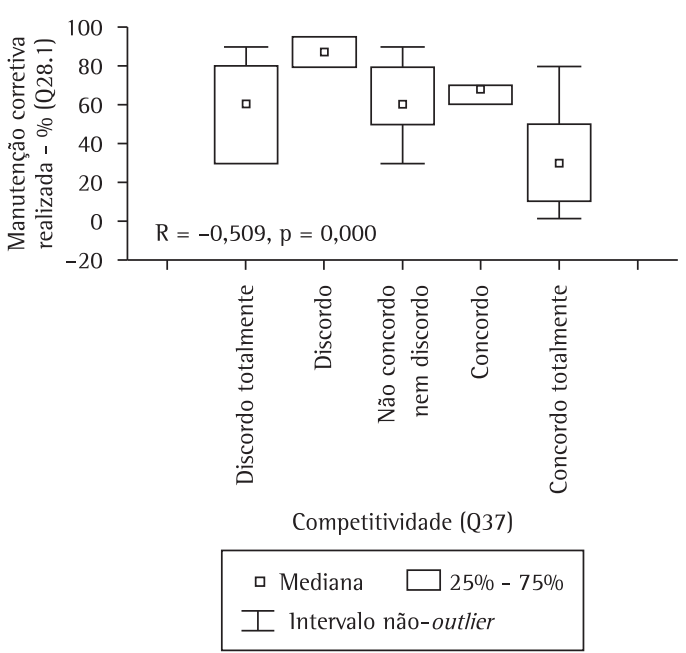

Figura 4. Porcentagem de manutenção corretiva realizada pelas Médias Empresas em relação à competitividade.

\subsection{Manutenção preditiva}

A realização de manutenção preditiva, da mesma forma que a preventiva, apresentou correlações positivas com algumas variáveis. A Figura 8 mostra que as Médias Empresas que utilizam software de apoio à gestão da manutenção realizam mais manutenções preditivas.

Outra relação encontrada nas Médias Empresas diz respeito às indústrias que concordam (conforme escala de cinco pontos da Tabela 8) que a manutenção traz vantagem competitiva para a organização: elas realizam mais manutenções preditivas (Figura 9).

Por fim, a última associação encontrada mostra que as empresas que concordam (conforme escala de cinco pontos da Tabela 8) que a manutenção é realizada

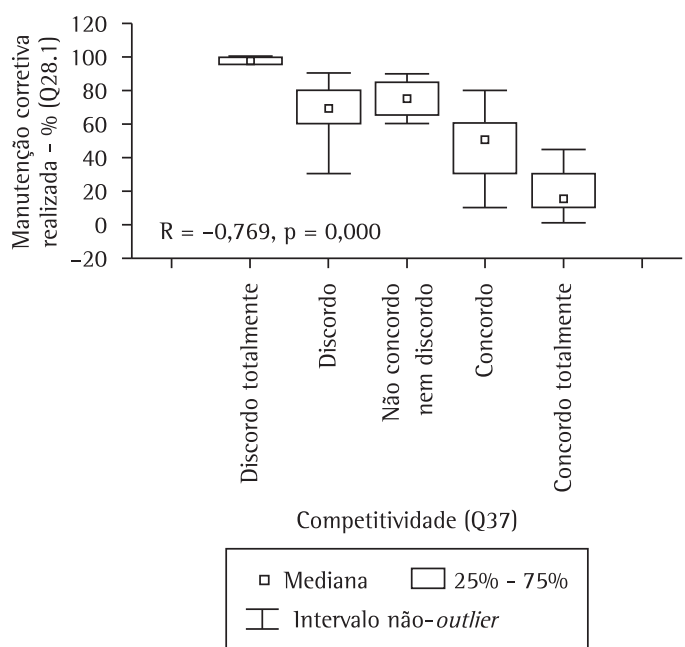

Figura 5. Porcentagem de manutenção corretiva realizada pelas Médias Empresas em relação ao planejamento.

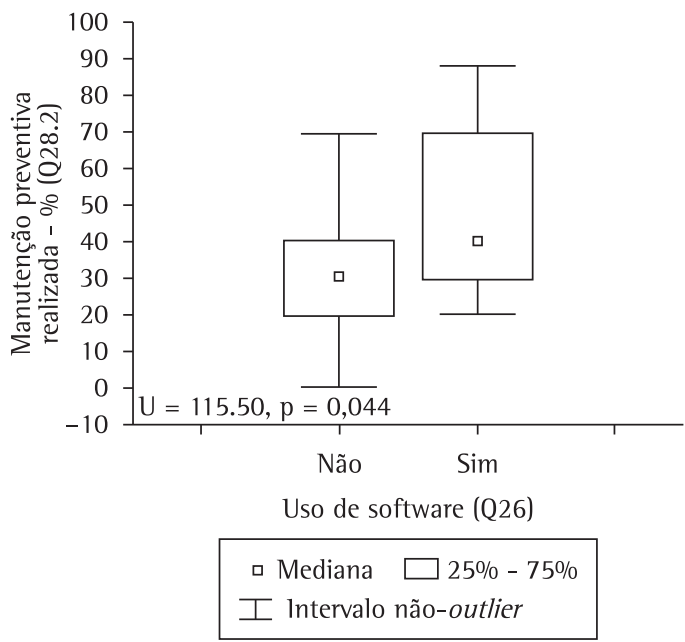

Figura 6. Porcentagem de manutenção preventiva realizada pelas Médias Empresas em relação ao uso de software de apoio à gestão da manutenção. 
de forma planejada realizam mais manutenção do tipo preditiva (Figura 10). A correlação encontrada foi positiva e moderada.

\subsection{Resultados encontrados nas Grandes Empresas}

Nesse estrato de empresas também foram encontradas algumas relações importantes, conforme a seguir:

- As empresas que realizam estudos de confiabilidade com os dados de falha dos equipamentos concordam (conforme escala de cinco pontos da Tabela 8) que a manutenção traz vantagem competitiva para a organização;

- As empresas que realizam estudos de mantenabilidade com os dados de reparo dos equipamentos concordam (conforme escala de cinco pontos da Tabela 8) que a manutenção traz vantagem competitiva para a organização; e

- As empresas que concordam (conforme escala de cinco pontos da Tabela 8) que a manutenção é realizada de forma planejada realizam menos manutenções corretivas e mais manutenções preventivas.

\section{Hipótese construída}

Foi construída uma hipótese que envolve a questão da competitividade conforme a seguir:

H1: A percepção do potencial estratégico da manutenção como fonte de vantagem competitiva está positivamente relacionada com o tratamento dado à manutenção.

No que diz respeito à construção da hipótese, partiu-se para investigar o tratamento dado à área de manutenção por empresas que veem a manutenção

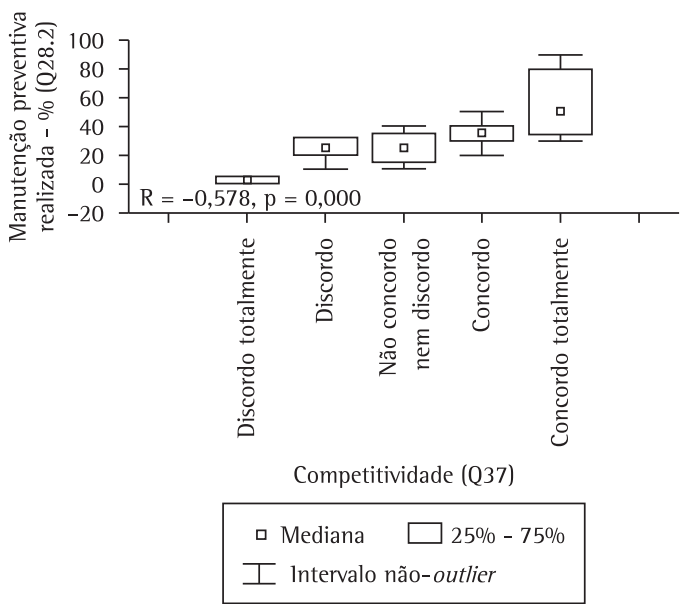

Figura 7. Porcentagem de manutenção preventiva realizada pelas Médias Empresas em relação ao planejamento da manutenção. como fonte de vantagem competitiva. Perguntou-se aos gerentes: "A área de manutenção traz vantagem competitiva para sua organização?” As opções de resposta eram sim ou não.

0 gerente da manutenção foi questionado se a área de manutenção traz vantagem competitiva para sua organização. Para aqueles que a consideram fonte de vantagem competitiva procedeu-se à investigação de algumas variáveis que representam um tratamento positivo dado à área de manutenção. Foram elas:

- A realização de estudos ou pesquisas sobre a estratégia de manutenção;

- 0 alinhamento entre a estratégia de manutenção e a estratégia da organização;

- Planejamento de manutenção;

- A porcentagem de cada ação de manutenção realizada (corretiva, preventiva e preditiva);

- A utilização da metodologia RCM;

- A realização de treinamento; e

- A coleta e o tratamento de dados de falha e de reparo dos equipamentos.

A escolha dessas variáveis teve origem na observação das características do setor de manutenção bem como na realização de uma pesquisa na literatura, na qual foi possível verificar a ênfase dada a essas variáveis, como se pode verificar a seguir.

Sherwin (2000), em seu artigo sobre modelos de gestão da manutenção, enfatiza a importância da coleta detalhada de dados sobre a operação, manutenção, falhas, etc. Ele diz que sem esses dados não é possível aplicar nenhum modelo matemático. E, ainda, acredita que a implementação de tais

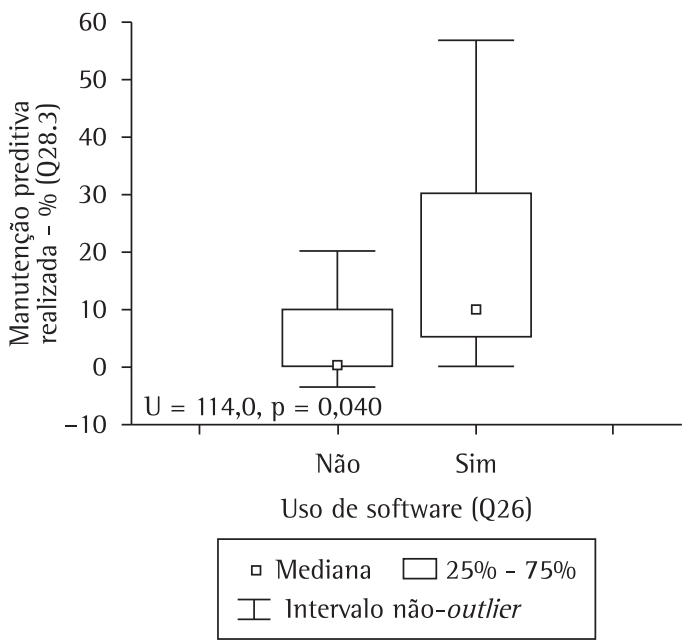

Figura 8. Porcentagem de manutenção preditiva realizada pelas Médias Empresas em relação ao uso de software de apoio à gestão da manutenção. 


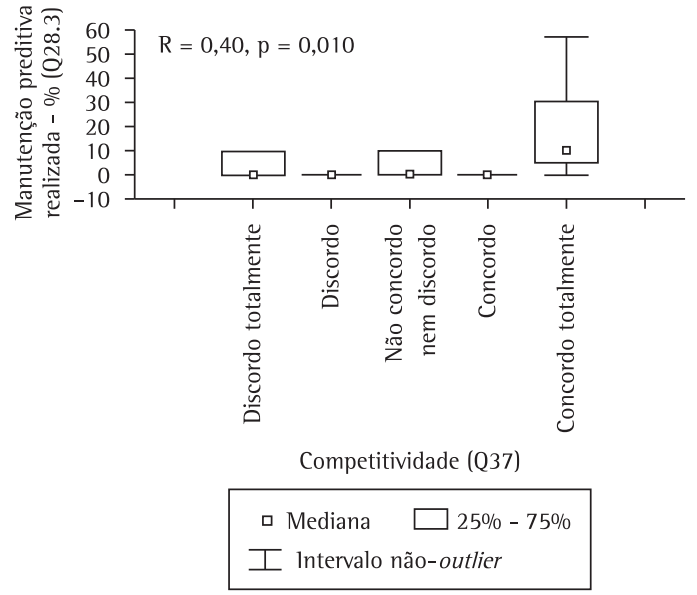

Figura 9. Porcentagem de manutenção do tipo preditiva realizada pelas Médias Empresas em relação à competitividade.

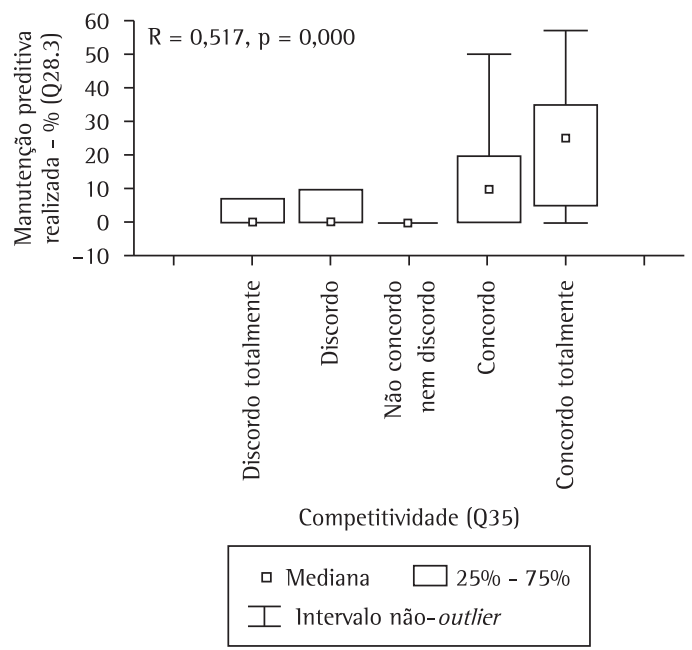

Figura 10. Porcentagem de manutenção preditiva realizada pelas Médias Empresas em relação ao planejamento.

modelos pode trazer benefícios como "contribuição para os lucros".

A prática de ações de manutenção preditiva e preventiva, em vez da manutenção corretiva, é destacada por diversos autores. Um estudo proposto por Swanson (2003) examina as maneiras de lidar com a complexidade do ambiente de produção e o uso de práticas de manutenção que ajudam na gestão da informação e no processamento de requisitos que tal complexidade gera. 0 autor enfatiza que uma maneira de a função manutenção obter maior controle do seu trabalho e reduzir a incerteza é o uso das ações de manutenção preditiva e preventiva.

No que diz respeito às questões estratégicas de manutenção, a utilização de modelos como o RCM, que Eisinger e Rakowsky (2000) consideram como "bem sucedida" em diversas áreas da indústria, tem sido investigada.

A competitividade proporcionada pelos setores de manutenção das organizações proporciona um diferencial estratégico às organizações. Segundo Pintelon, Kumar e Vereecke (2006), uma intensa e competitiva pressão está levando muitas empresas a buscarem todas as possíveis fontes de vantagem competitiva e, por isso, é essencial compreender o potencial de cada função.

A Tabela 9 apresenta os testes estatísticos utilizados para identificar as associações entre as variáveis tratadas na hipótese $\mathrm{H} 1$, assim como as estatísticas dos testes e o $p$ valor.

A hipótese construída foi investigada separadamente, nas médias e grandes indústrias. Nas empresas em que o gestor vê a manutenção como uma potencial fonte de vantagem competitiva foram encontradas associações com diversas variáveis que definem esse padrão de comportamento. Elas refletem um tratamento positivo dado à manutenção, tanto para procedimentos quanto para questões estratégicas. Nas Médias Empresas em que os gestores percebem a manutenção como uma fonte de vantagem competitiva, o tratamento positivo dado à manutenção é explicado pelas seguintes variáveis:

- V1: 0 percentual de manutenção corretiva realizada;

- V2. 0 percentual de manutenção preventiva realizada;

- V3. A utilização da metodologia do RCM;

- V4. A empresa realizou recentemente algum estudo ou pesquisa sobre a estratégia de manutenção;

- V5. A equipe de manutenção recebe treinamento;

- V6. Acredita-se que a estratégia de manutenção está alinhada à estratégia organizacional;

- V7. A manutenção é realizada de forma planejada. Nas Grandes Empresas onde a manutenção é vista como uma potencial fonte de vantagem competitiva, o foco principal da gestão da manutenção é a coleta e análise de dados sobre falhas e reparos para estudos de confiabilidade e mantenabilidade, respectivamente. 0 tratamento positivo dado à manutenção é explicado pelas seguintes variáveis:

- V8. Estudos de confiabilidade são realizados em dados de falha de equipamento;

- V9. Estudos de mantenabilidade são conduzidos em dados de reparo de equipamentos.

\subsection{Discussão sobre a hipótese construída}

0 tratamento dado à área de manutenção mostrou uma relação positiva com a percepção da gerência quanto à competitividade que pode ser proporcionada pela gestão da manutenção. Esse tratamento foi 
Tabela 9. Estatísticas referentes à percepção dos gerentes quanto à competitividade da manutenção.

\begin{tabular}{|c|c|c|c|c|c|}
\hline $\begin{array}{l}\text { Porte da } \\
\text { indústria }\end{array}$ & Variavel & Variavel & Teste & Estatística & $p$ valor \\
\hline Médio & $\begin{array}{l}\text { Percentual de manutenção corretiva } \\
\text { realizada (V1) }\end{array}$ & $\begin{array}{l}\text { A manutenção é vista como uma fonte de } \\
\text { vantagem competitiva para organização }\end{array}$ & Spearman Correlation & $R=-0.509$ & 0.000 \\
\hline Médio & $\begin{array}{l}\text { Percentual de manutenção preditiva } \\
\text { realizada }(\mathrm{V} 2)\end{array}$ & $\begin{array}{l}\text { A manutenção é vista como uma fonte de } \\
\text { vantagem competiutiva para organização }\end{array}$ & Spearman Correlation & $R=0.400$ & 0.010 \\
\hline Médio & Utilização da metodologia RCM (V3) & $\begin{array}{l}\text { A manutenção é vista como uma fonte de } \\
\text { vantagem competiutiva para organização }\end{array}$ & Mann-Whitney & $\mathrm{U}=51$ & 0.039 \\
\hline Médio & $\begin{array}{l}\text { A empresa realizou recentemente } \\
\text { algum estudo ou pesquisa sobre } \\
\text { estratégia da manutenção (V4) }\end{array}$ & $\begin{array}{l}\text { A manutenção é vista como uma fonte de } \\
\text { vantagem competiutiva para organização }\end{array}$ & Mann-Whitney & $\mathrm{U}=87$ & 0.049 \\
\hline Médio & $\begin{array}{l}\text { A equipe de manutenção recebe } \\
\text { treinamento }(\mathrm{V} 5)\end{array}$ & $\begin{array}{l}\text { A manutenção é vista como uma fonte de } \\
\text { vantagem competiutiva para organização }\end{array}$ & Mann-Whitney & $\mathrm{U}=48$ & 0.040 \\
\hline Médio & $\begin{array}{l}\text { Acredita-se que a estratégia da } \\
\text { manutenção está alinhada à } \\
\text { estratégia organizacional (V6) }\end{array}$ & $\begin{array}{l}\text { A manutenção é vista como uma fonte de } \\
\text { vantagem competiutiva para organização }\end{array}$ & Spearman Correlation & $R=0.445$ & 0.003 \\
\hline Médio & $\begin{array}{l}\text { A manutenção é realizada de forma } \\
\text { planejada (V7) }\end{array}$ & $\begin{array}{l}\text { A manutenção é vista como uma fonte de } \\
\text { vantagem competiutiva para organização }\end{array}$ & Spearman Correlation & $R=0.430$ & 0.005 \\
\hline Grande & $\begin{array}{l}\text { Estudos de confiabilidade são } \\
\text { realizados em dados de falha de } \\
\text { equipamentos (V8) }\end{array}$ & $\begin{array}{l}\text { A manutenção é vista como uma fonte de } \\
\text { vantagem competiutiva para organização }\end{array}$ & Mann-Whitney & $\mathrm{U}=4.0$ & 0.045 \\
\hline Grande & $\begin{array}{l}\text { Estudos de mantenabilidade são } \\
\text { realizados em dados dereparo de } \\
\text { equipamentos (V9) }\end{array}$ & $\begin{array}{l}\text { A manutenção é vista como uma fonte de } \\
\text { vantagem competiutiva para organização }\end{array}$ & Mann-Whitney & $\mathrm{U}=4.1$ & 0.045 \\
\hline
\end{tabular}

representado por algumas variáveis identificadas após a análise estatística (Tabela 9).

Foi constatado que as Médias Empresas que veem a manutenção como fonte de vantagem competitiva conduziram recentemente algum estudo ou pesquisa sobre a estratégia de manutenção. Observou-se, também, que essas empresas concordam que a estratégia de manutenção deve estar alinhada à estratégia da organização.

Quanto ao uso de metodologias e ferramentas de apoio, foi observado que as Médias Empresas que veem a manutenção como fonte de vantagem competitiva utilizam a metodologia RCM. Aquelas que não utilizam RCM não mostraram qualquer comportamento especial em relação à competitividade organizacional. Percebeu-se que as Médias Empresas que acreditam que a manutenção traz vantagem competitiva realizam menos manutenções corretivas e, por outro lado, mais manutenções preditivas.

No que diz respeito aos treinamentos realizados com os funcionários, observou-se que nas Médias Empresas em que a administração acredita que a manutenção traz vantagem competitiva para a organização mais sessões de treinamento foram dirigidas aos profissionais de manutenção.

Finalmente, com relação às Grandes Empresas, observou-se que o foco principal para as empresas que consideram a manutenção fonte de vantagem competitiva é a realização de estudos de confiabilidade e mantenabilidade nos dados de falha e reparo dos equipamentos.

\section{Discussão}

De modo geral observa-se que ainda há muito a se fazer para a obtenção de melhores indicadores na manutenção das Médias Empresas. Muitas delas utilizam como ferramenta principal a experiência gerencial em detrimento de ferramentas analíticas mais poderosas para a solução de problemas e para apoiar a gestão. Os recursos que podem ser alocados para auxiliar a gerência são muitos, porém não é dada a devida atenção ao uso que pode ser feito deles e, consequentemente, aos resultados que podem ser obtidos com a sua utilização.

$\mathrm{Na}$ análise exploratória das Médias Empresas, com relação à porcentagem de utilização das ações de manutenção, é interessante observar a ideia de que o planejamento, a competitividade e a utilização de software estão relacionados aos bons indicadores das ações de manutenção utilizadas, ou seja, essas variáveis estão relacionadas com uma menor realização de manutenções corretivas e uma maior realização de manutenções preventivas e preditivas. Mesmo diante desse comportamento observa-se que ainda é expressiva a quantidade de manutenções corretivas realizadas, o que sugere que as indústrias deveriam dispensar uma maior atenção a esse fator com o intuito de evitar paradas desnecessárias e sem planejamento, o que, consequentemente, pode afetar o desempenho da produção.

As Grandes Empresas mostraram melhores índices quando comparadas às médias. Observou-se que é dispensada uma maior atenção à coleta e ao 
tratamento dos dados, assim como há uma maior utilização das metodologias e ferramentas direcionadas à manutenção.

Diante do exposto, este trabalho pôde proporcionar conhecimento sobre o que, de fato, vem sendo realizado na manutenção das indústrias da região investigada. Os resultados apontam para uma série de melhorias que um maior investimento nessa área pode proporcionar. Quando se fala em investimento é no sentido de prestar maior atenção ao que vem sendo feito na manutenção das indústrias, pois, pelo exposto neste trabalho, é possível observar que as deficiências nessa área (conforme os resultados da pesquisa) podem ser minimizadas se tratadas de forma direta.

Sobre a hipótese construída, observou-se que o tratamento dado à área de manutenção mostrou uma relação positiva com a percepção da gerência quanto à competitividade que pode ser proporcionada pela gestão da manutenção. Esse tratamento pôde ser explicado por algumas variáveis que representam práticas da manutenção e são mencionadas ao longo do texto.

\section{Conclusões}

A pesquisa realizada mostra resultados de uma investigação sobre a gestão da manutenção na região metropolitana de Recife. Esses resultados são de grande importância por gerarem um maior conhecimento nessa área, visto que nesta pesquisa foi utilizada a amostragem probabilística, o que possibilita generalizar os resultados encontrados na análise dos dados para a população investigada.

Alguns dos resultados encontrados puderam ser observados em outras pesquisas realizadas com outras amostras. Porém, a população de empresas-alvo deste trabalho ainda não havia sido investigada, o que torna os resultados encontrados ainda mais relevantes. Além disso, não se podem generalizar os resultados de pesquisas realizadas em outros locais, com outras populações distintas da investigada neste trabalho para esta amostra. A estatística é uma ferramenta que permite testar alguns comportamentos, por vezes esperados, porém ainda não comprovados, e, além disso, avaliar a intensidade de algumas relações entre as variáveis.

As relações encontradas são de grande utilidade para o setor produtivo, por mostrar algumas deficiências (como, por exemplo, a grande utilização de manutenções do tipo corretiva e a pouca utilização das metodologias de gestão existentes) na manutenção dos setores industriais investigados. Isso possibilita uma análise mais crítica e detalhada dos gestores e o direcionamento de sua atenção para as variáveis apresentadas neste trabalho, que apresentam maior impacto em questões estratégicas e de planejamento e nas práticas utilizadas.

\section{Limitações e sugestões para trabalhos futuros}

Como limitação do presente estudo destaca-se a falta de algum estudo semelhante que pudesse servir da base inicial de informação no que se refere à variância das variáveis analisadas, o que é importante para cálculo do tamanho da amostra. Diante desse cenário recorreu-se à amostragem-piloto, conforme descrito na metodologia do trabalho.

A seguir, são propostas recomendações cujo objetivo é dar continuidade ao presente trabalho e contribuir para o desenvolvimento da gestão da manutenção nas empresas:

- A aplicação do questionário desenvolvido no presente trabalho, de forma mais abrangente, em estratos distintos para cada ramo de atividade; e

- A realização desta pesquisa em âmbito nacional, em setores específicos da economia.

\section{Referências}

ALMEIDA, A. T. Modelagem Multicritério para Seleção de Intervalos de Manutenção Preventiva Baseada na Teoria da Utilidade Multiatributo. Pesquisa Operacional, v. 25, n. 1, p. 69-81, 2005. http://dx.doi.org/10.1590/S010174382005000100005

ALMEIDA, A. T. Repair Contract Decision Model Trough Additive Utility Function. Journal of Quality in Maintenance Engineering, v. 7, n. 1, p. 42-48, 2001. http://dx.doi.org/10.1108/13552510110386883

ALMEIDA, A. T.; BOHORIS, G. A. Decision Theory in Maintenance. Journal of Quality in Maintenance Engineering, v. 1, n. 1, p. 39-45, 1995. http://dx.doi. org/10.1108/13552519510083138

ASSOCIAÇÃO BRASILEIRA DE MANUTENÇÃO - ABRAMAN. Disponivel em: <http://www.abraman.org.br/>. Acesso em: 15 fev. 2007.

ASSOCIAÇÃO BRASILEIRA DE NORMAS TÉCNICAS - ABNT. NBR-5462: Confiabilidade e Mantenabilidade. Rio de Janeiro: ABNT, 1994.

BARBETTA, P. A.; REIS, M. M.; BORNIA, A. C. Estatística para cursos de engenharia e informática. São Paulo: Atlas, 2004.

BARBOSA, G. R. ; ALMEIDA, A. T. ; COSTA, A. P. S. SAD: Análise da percepção de usuários e desenvolvedores através de técnicas estatísticas multivariadas. Produção, v. 16, n. 2, p. 216-228, 2006.

CAVAlCANTE, C. A. V.; AlMEIDA, A. T. A Multicriteria Decision Aiding Model Using Promethee 111 For Preventive Maintenance Planning Under Uncertain Conditions. Journal of Quality in Maintenance Engineering, v. 13, p. 385-397, 2007. http://dx.doi. org/10.1108/13552510710829470

CAVALCANTE, C. A. V.; ALMEIDA, A. T. Modelo multicritério de apoio a decisão para o planejamento de manutenção preventiva utilizando PROMETHEE 11 em situações 
de incerteza. Pesquisa Operacional, v. 25, n. 2, p. 279-296, 2005.

CHOLASUKE, C.; BHARDWA, R.; ANTONY, J. The status of maintenance management in UK manufacturing organizations: results from a pilot survey. Journal of Quality in Maintenance Engineering, v. 10, n. 1, p. 5-15, 2004. http://dx.doi.org/10.1108/13552510410526820

ClERICUZI, A. Z.; ALMEIDA, A. T.; COSTA, A. P. C. S. Aspectos relevantes dos SAD nas organizações: um estudo exploratório. Produção, v. 16, n. 1, p. 8-23, 2006. http://dx.doi.org/10.1590/S0103-65132006000100002

COCHRAN, W. G. Sampling Thechniques. New York: Wiley, 1977.

EISINGER, S.; RAKOWSKY, U. K. Modeling of uncertainties in reliability centered maintenance - a probabilistic approach. Reliability Engineering \& System Safety, v. 71, p. 159-64, 2000. http://dx.doi.org/10.1016/S09518320(00)00088-0

GARG, A.; DESHMUKH, S. G. Maintenance Management: literature review and directions. Journal of Quality in Maintenance Engineering, v. 12, n. 3, p. 205-238, 2006. http://dx.doi.org/10.1108/13552510610685075

GR00TE, P. Maintenance performance analysis: a practical approach. Journal of Quality in Maintenance Engineering, v. 1, n. 2, p. 4-24, 1995. http://dx.doi. org/10.1108/13552519510089556

HAIR JUNIOR, J. F. et al. Fundamentos de métodos de pesquisa em administração. São Paulo: Bookman, 2005.

INSTITUTO BRASILEIRO DE GEOGRAFIA E ESTATISTICA - IBGE. Disponível em: <http://www.ibge. gov.br/home/>. Acesso em: 15 fev. 2007.

JONSSON, P. The status of maintenance management in Swedish manufacturing firms. Journal of Quality in Maintenance Engineering, v. 3, n. 4, p. 233-58, 1997. http://dx.doi.org/10.1108/13552519710176863

KHAN, F. 1.; HADDARA, M. Risk-Based Maintenance (RBM): A New Approach for Process Plant Inspection and Maintenance. Wiley InterScience, v. 23, n. 4, p. 252-265, 2004.

O'CONNOR, P. D. T. Pratical Reliability Engineering. London: WIP, 2005.

PARIDA,A.;KUMAR,U.Maintenanceperformancemeasurement (MPM): issues and challenges. Journal of Quality in Maintenance Engineering, v. 12, n. 3, p. 239-51, 2006. http://dx.doi.org/10.1108/13552510610685084

PINTELON, L.; KUMAR, P. S.; VEREECKE, A. Evaluating the effectiveness of maintenance strategies. Journal of Quality in Maintenance Engineering, v. 12, n. 1, p. 7-20, 2006. http://dx.doi.org/10.1108/13552510610654501

PORTER, M. E. Vantagem Competitiva - criando e sustentando um desempenho superior. Rio de Janeiro: Campus, 1992.

REIS, A. C. B.; COSTA, A. P. C. S.; ALMEIDA, A. T. Planning and competitiveness in maintenance management: An exploratory study in manufacturing companies. Journal of Quality in Maintenance Engineering, v. 15, p. 259-270, 2009 http://dx.doi. org/10.1108/13552510910983206

SANTOS, C. M. P. Modelos de manutenção - ênfase na confiabilidade e mantenabilidade. In: ALMEIDA, A. T.; SOUZA, F. M. C. Gestão da manutenção na direção da competitividade. Recife: Universitária, 2001.

SEBRAE. Critérios de classificação de empresas: El - ME - EPP quanto ao número de empregados. 2006. Disponível em: <http://www.sebraec.com.br/leis/default. asp?vcdtexto $=4154>$.

SHERWIN, D. A review of overall models for maintenance management. Journal of Quality in Maintenance Engineering, v. 6, n. 3, p. 138-64, 2000. http://dx.doi. org/10.1108/13552510010341171

SIEGEL, S.; CASTELLAN, N. Nonparametric Statistics for the Behavioral Sciences. New York: McGraw-Hill, 1988.

SIQUEIRA, 1. P. Manutenção centrada na confiabilidade. Rio de Janeiro: Qualitymark, 2005.

STATSOFT. STATISTICA: data analysis software system. version 6. StatSoft, 2001.

STEVENSON, W. J. Operations management. New York: McGraw-Hill, 2002.

SUKHATME, P. V.; SUKHATME, B. V. Sampling Theory of surveys with applications. lowa State University Press, 1970.

SWANSON, L. An information-processing model of maintenance management. International Journal of Production Economics, v. 83, p. 45-64, 2003. http:// dx.doi.org/10.1016/S0925-5273(02)00266-9

SZAJUBOK, N. K.; ALENCAR, L. H.; ALMEIDA, A. T. Modelo de gerenciamento de materiais na construção civil utilizando avaliação multicritério. Produção, v.16, n. 2, p. 303-318, 2006. http://dx.doi.org/10.1590/S010365132006000200010

VALOIS, U.; ALMEIDA, A. T. Modelo de apoio à decisão multicritério para terceirização de atividades produtivas baseado no método SMARTS. Produção, v. 19, n. 2, p. 249-260, 2009. http://dx.doi.org/10.1590/S010365132009000200003

\section{Diagnosis of maintenance management in medium and large industries in the metropolitan area of Recife}

\section{Abstract}

This article presents the results of a research study on maintenance management practices in medium and large manufacturing industries in the metropolitan area of Recife, in various branches of activity. The survey was carried out by means of in loco application of questionnaires addressing important issues dealing with the context of maintenance. The 50 industries surveyed were selected by probability sampling, where sampling framework was drawn from the records of the Federation of Industries of the State of Pernambuco, in 2005 and 2006. The interviews were conducted during the second and third quarters of 2007. Among the results, it is possible to state that maintenance has presented some shortcomings, which can be mitigated or even overcome through greater attention to the sector. Moreover, it is possible to note that most industries use experience as a management tool, at the expense of more efficient analytical techniques for solving problems. This behavior limits the positive results that can be obtained from an appropriate treatment to maintenance.

\section{Keywords}

Maintenance management. Maintenance strategy. Maintenance planning. 


\section{Apêndice 1. Correlação entre as variáveis}

Tabela 10. Variáveis das Médias Empresas que estão correlacionadas; testes utilizados; estatísticas dos testes e o respectivo $p$ valor.

\begin{tabular}{clccc}
\hline Variável 1 & \multicolumn{1}{c}{ Variável 2 } & Teste & Estatística & $p$ valor \\
\hline Usa software & A manutenção é vista como uma fonte de vantagem competitiva para a organização & Mann-Whitney & $\mathrm{U}=72,0$ & 0,001 \\
Usa software & Acredita-se que a estratégia da manutenção está alinhada à estratégia da empresa & Mann-Whitney & $\mathrm{U}=91,5$ & 0,007 \\
Usa software & Porcentagem de manutenção corretiva realizada & Mann-Whitney & $\mathrm{U}=92,0$ & 0,007 \\
Usa software & Porcentagem de manutenção preventiva realizada & Mann-Whitney & $\mathrm{U}=115,5$ & 0,044 \\
Usa software & Porcentagem de manutenção preditiva realizada & Mann-Whitney & $\mathrm{U}=114,0$ & 0,040 \\
Usa software & O gerente concorda que a manutenção da empresa é realizada de forma planejada & Mann-Whitney & $\mathrm{U}=113,0$ & 0,037 \\
\hline
\end{tabular}

Tabela 11. Variáveis das Médias Empresas que estão correlacionadas; testes utilizados; estatísticas dos testes e o respectivo $p$ valor.

\begin{tabular}{|c|c|c|c|c|}
\hline Variável 1 & Variável 2 & Teste & Estatistica & $p$ valor \\
\hline $\begin{array}{l}0 \text { gerente concorda que a manutenção da } \\
\text { empresa é realizada de forma planejada }\end{array}$ & $\begin{array}{l}\text { Porcentagem de manutenção corretiva } \\
\text { realizada }\end{array}$ & Correlação de Spearman & $R=-0,769$ & 0,000 \\
\hline $\begin{array}{l}0 \text { gerente concorda que a manutenção da } \\
\text { empresa é realizada de forma planejada }\end{array}$ & $\begin{array}{l}\text { Porcentagem de manutenção preventiva } \\
\text { realizada }\end{array}$ & Correlação de Spearman & $R=0,578$ & 0,000 \\
\hline $\begin{array}{l}0 \text { gerente concorda que a manutenção da } \\
\text { empresa é realizada de forma planejada }\end{array}$ & $\begin{array}{l}\text { Porcentagem de manutenção preditiva } \\
\text { realizada }\end{array}$ & Correlação de Spearman & $R=0,517$ & 0,000 \\
\hline $\begin{array}{l}0 \text { gerente concorda que a manutenção da } \\
\text { empresa é realizada de forma planejada }\end{array}$ & Utilização da metodologia RCM & Mann-Whitney & $\mathrm{U}=43,0$ & 0,025 \\
\hline
\end{tabular}

Tabela 12. Variáveis das Médias Empresas que estão correlacionadas; testes utilizados; estatísticas dos testes e o respectivo $p$ valor.

\begin{tabular}{|c|c|c|c|c|}
\hline Variável 1 & Variável 2 & Teste & Estatística & $p$ valor \\
\hline $\begin{array}{l}\text { A manutenção é vista como fonte de } \\
\text { vantagem competitiva para a organização }\end{array}$ & $\begin{array}{l}\text { A empresa fez recentemente algum estudo } \\
\text { ou pesquisa sobre estratégia da manutenção }\end{array}$ & Mann-Whitney & $\mathrm{U}=87,0$ & 0,049 \\
\hline $\begin{array}{l}\text { A manutenção é vista como fonte de } \\
\text { vantagem competitiva para a organização }\end{array}$ & Utilização da metodologia RCM & Mann-Whitney & $\mathrm{U}=51,0$ & 0,039 \\
\hline $\begin{array}{l}\text { A manutenção é vista como fonte de } \\
\text { vantagem competitiva para a organização }\end{array}$ & $\begin{array}{l}0 \text { pessoal da manutenção recebe } \\
\text { treinamentos }\end{array}$ & Mann-Whitney & $\mathrm{U}=48,0$ & 0,040 \\
\hline $\begin{array}{l}\text { A manutenção é vista como fonte de } \\
\text { vantagem competitiva para a organização }\end{array}$ & $\begin{array}{l}\text { Porcentagem de manutenção corretiva } \\
\text { realizada }\end{array}$ & Correlação de Spearman & $R=-0,509$ & 0,000 \\
\hline $\begin{array}{l}\text { A manutenção é vista como fonte de } \\
\text { vantagem competitiva para a organização }\end{array}$ & $\begin{array}{l}\text { Porcentagem de manutenção preditiva } \\
\text { realizada }\end{array}$ & Correlação de Spearman & $R=0,400$ & 0,010 \\
\hline $\begin{array}{l}\text { A manutenção é vista como fonte de } \\
\text { vantagem competitiva para a organização }\end{array}$ & $\begin{array}{l}\text { Acredita-se que a estratégia da manutenção } \\
\text { está alinhada à estratégia da empresa }\end{array}$ & Correlação de Spearman & $R=0,445$ & 0,003 \\
\hline $\begin{array}{l}\text { A manutenção é vista como fonte de } \\
\text { vantagem competitiva para a organização }\end{array}$ & $\begin{array}{l}0 \text { gerente concorda que a manutenção da } \\
\text { empresa é realizada de forma planejada }\end{array}$ & Correlação de Spearman & $R=0,430$ & 0,005 \\
\hline
\end{tabular}

Tabela 13. Variáveis das Grandes Empresas que estão correlacionadas; testes utilizados; estatísticas dos testes e o respectivo $p$ valor.

\begin{tabular}{|c|c|c|c|c|}
\hline Variável 1 & Variável 2 & Teste & Estatística & $p$ valor \\
\hline $\begin{array}{l}\text { São realizados estudos de confiabilidade } \\
\text { com os dados de falha dos equipamentos }\end{array}$ & $\begin{array}{l}\text { A manutenção é vista como fonte de } \\
\text { vantagem competitiva para a organização }\end{array}$ & Mann-Whitney & $\mathrm{U}=4,0$ & 0,045 \\
\hline $\begin{array}{l}\text { São realizados estudos de mantenabilidade } \\
\text { com os dados de reparo dos equipamentos }\end{array}$ & $\begin{array}{l}\text { A manutenção é vista como fonte de } \\
\text { vantagem competitiva para a organização }\end{array}$ & Mann-Whitney & $\mathrm{U}=4,1$ & 1,045 \\
\hline $\begin{array}{l}0 \text { gerente concorda que a manutenção da } \\
\text { empresa é realizada de forma planejada }\end{array}$ & $\begin{array}{l}\text { Porcentagem de manutenção corretiva } \\
\text { realizada }\end{array}$ & Correlação de Spearman & $R=-0,905$ & 0,000 \\
\hline $\begin{array}{l}0 \text { gerente concorda que a manutenção da } \\
\text { empresa é realizada de forma planejada }\end{array}$ & $\begin{array}{l}\text { Porcentagem de manutenção preventiva } \\
\text { realizada }\end{array}$ & Correlação de Spearman & $R=0,674$ & 0,033 \\
\hline
\end{tabular}

